\title{
Modalities of ventricular pacing for cardiac resynchronization therapy in patients with heart failure: a meta-analysis and systematic review
}

\author{
Ailan Chen ${ }^{1}$, Xinyu Chen ${ }^{2}$, Yuechun Shen ${ }^{1}$, Wanglin Li ${ }^{3}$
}

\author{
'Department of Cardiology, The First Affiliated Hospital of Guangzhou Medical \\ University, Guangzhou, China \\ 2Department of Pathogenic Biology, Guangzhou Hoffmann Institute of Immunology, \\ Guangzhou Medical University, Guangzhou, China \\ ${ }^{3}$ Department of Gastrointestinal Surgery, Guangzhou First People's Hospital, \\ Guangzhou Medical University, Guangzhou, China
}

Submitted: 7 April 2016

Accepted: 27 August 2016

Arch Med Sci 2017; 13, 5: 1006-1017

DOI: https://doi.org/10.5114/aoms.2017.65660

Copyright @ 2017 Termedia \& Banach

\section{Abstract}

Introduction: This meta-analysis evaluated 14 studies which compared clinical and functional outcomes after different cardiac resynchronization therapy (CRT) modalities.

Material and methods: Relevant studies were selected from the Medline, PubMed, Cochrane, and Google Scholar databases until June 27 2016. We analyzed and compared the clinical outcomes (peak $\mathrm{O}_{2}$ consumption and LVEF) and functional outcomes (6-min walk distance and quality of life (SF-36)) of HF patients who received different CRT modalities with outcomes in patients who received conventional univentricular therapy.

Results: There was no significant difference in post-treatment 6-min walking distance between the biventricular (BiV) and left/right univentricular (LUV/RUV) groups (standardized difference in means $=0.049,95 \% \mathrm{Cl}$ : -0.119 to $0.217, p=0.566$ ), or between the BiV and triventricular (TriV) groups (standardized difference in means $=0.035,95 \% \mathrm{Cl}:-0.270$ to 0.340 , $p=0.822$ ). Peak $\mathrm{O}_{2}$ consumption was comparable between BiV and LUV/RUV groups (standardized difference in means $=0.306,95 \% \mathrm{Cl}:-0.002$ to 0.614 , $p=0.052$ ). Patients in the TriV group had a significant improvement in LVEF compared to the BiV group (standardized difference in means $=0.647$, $95 \% \mathrm{Cl}: 0.313$ to $0.982, p<0.001)$.

Conclusions: TriV CRT is an attractive alternative to univentricular or BiV pacing for heart failure patients. It is necessary to conduct further large randomized trials to validate our present data.

Key words: heart failure, cardiac resynchronization therapy, biventricular, triventricular, left ventricular ejection fraction.

\section{Introduction}

Cardiovascular disease is the leading cause of mortality in the world, with more than 22 million people suffering from heart failure (HF) [1]. The New York Heart Association (NYHA) classification system categorizes HF patients into class I-IV based on the degree of effort needed to elicit symptoms [2].

A number of cardiac devices are used to achieve hemodynamic improvement in HF patients. Patients who require pacing for atrioventric-

\author{
Corresponding authors: \\ Ailan Chen MD, PhD \\ Department of Cardiology \\ The First Affiliated \\ Hospital of Guangzhou \\ Medical University \\ Guangzhou 510120, China \\ Phone: +86 13719198832 \\ E-mail: 1228327958@qq.com \\ Wanglin Li \\ Department of \\ Gastrointestinal Surgery, \\ Guangzhou First People's \\ Hospital \\ Guangzhou Medical \\ University \\ Guangzhou 510180, China \\ Phone: +86 13794365151 \\ Fax: 020-83389471 \\ E-mail: 421255910@qq.com
}


ular block or bradycardia after coronary artery bypass grafting (CABG) are now routinely treated with right univentricular (RUV) pacing. However, RUV has been shown to result in dyssynchrony between the two ventricles, arrhythmias, and HF $[3,4]$. Cardiac resynchronization therapy (CRT) achieves coordinated pacing of the left and right ventricles by addition of a left ventricular (LV) pacing lead to a pacemaker or defibrillator system which includes a right ventricular (RV) and possibly a right atrial lead [5]. Targeted resynchronization therapy in the early period after cardiac surgery was shown to reduce morbidity and mortality in HF patients [6], and CRT is currently the recommended therapy for selected patients who have refractory HF with systolic dysfunction and a QRS duration $\geq 120$ ms on optimal medical therapy [7].

The three major CRT modalities are: 1) simultaneous biventricular (BiV) pacing, 2) sequential BiV pacing where the timing of RV and LV stimulation is programmed to allow one ventricle to be activated before the other, and 3) LV pacing. A number of studies have compared outcomes of different CRT modalities. Left univentricular pacing (LUV) was shown to significantly improve peak oxygen consumption, 6-minute walk distance and the quality of life in chronic HF patients who had LV systolic dysfunction and QRS interval > $150 \mathrm{~ms}$ [8]. Patients who received RUV pacing showed more pronounced progression of heart failure symptoms compared to patients who received BiV pacing [9, 10], and BiV has been shown to prevent adverse remodeling induced by RUV pacing [11]. BiV, when used as adjunctive therapy to pharmacologic strategies, reduced the risk of sudden cardiac death, and reduced hospitalization rates in patients classified as NYHA class III or IV, who had an ejection fraction of $35 \%$ or less $[12,13]$. Increased heart rate was recently shown to be significantly associated with enhanced contractility in patients receiving BiV pacing compared to those receiving single-site RUV or LUV stimulation [14], and the rise in contractility with increasing stimulation rates was higher for BiV compared to univentricular pacing [15]. The BiV was associated with a significant clinical benefit and lower mortality compared to isolated left ventricular pacing [16].

In contrast, other studies reported no significant difference in clinical benefits between LUV pacing and BiV pacing $[17,18]$. Left univentricular pacing pacing was also non-inferior to BiV with respect to improvement in NYHA class and reverse remodeling [19-21]. Additionally, it was recently reported that LV electrical delay, which is a predictor of the acute hemodynamic response to CRT, was independent of the pacing strategy [22]. Studies have also reported that tri-ventricular CRT configurations (TriV) using two RV leads and one LV lead [23] or one RV lead and two LV leads [24] were shown to be safe, effective, and provided a benefit in ventricular remodeling compared to conventional CRT.

In this study, we analyzed the findings from 14 different studies which compared the clinical outcomes (peak $\mathrm{O}_{2}$ consumption and LVEF) and functional outcomes (6-min walk distance and quality of life (SF-36)) of HF patients who received different CRT modalities with outcomes in patients who received conventional univentricular therapy.

\section{Material and methods}

This meta-analysis analyzed data from 14 studies which compared clinical outcomes and functional outcomes in congestive heart failure (CHF) patients who received biventricular with those who received univentricular (either left or right ventricular) stimulation for CRT. Studies that compared bi-ventricular versus tri-ventricular pacing were also included. The Medline, PubMed, Cochrane, and Google Scholar databases were searched (until June $\left.27^{\text {th }}, 2016\right)$ using the keywords heart failure, atrial fibrillation, cardiac resynchronization therapy, biventricular, quality of life, and functional status. Reference lists of relevant studies were hand-searched.

\section{Selection criteria}

Inclusion criteria were: 1) randomized controlled studies, including cross-over RCTs, 2) studies reporting on heart failure (any stage) with/ without atrial fibrillation (including all grades of $A F), 3$ ) intervention studies on resynchronization therapy (including CRT-D, CRT-P, etc.) which compared the efficacy of univentricular (mainly LUV), biventricular, and triventricular pacing.

Exclusion criteria were: 1) studies with no quantitative primary outcome. Prospective studies, retrospective studies, single arm studies, case control studies, cohort studies, letters, comments, editorials, case reports, proceedings, and personal communications were excluded.

\section{Study selection and data extraction}

Studies were identified by two independent reviewers. Where there was uncertainty regarding eligibility, a third reviewer was consulted. The study selection procedure is presented in Figure 1. Data extracted from the studies which met the eligibility criteria included the name of the first author, year of publication, study design, number of participants in each group, participants' age and gender, and the major outcomes.

\section{Quality assessment}

The Cochrane Collaboration's tool was used to assess the quality of the included studies. Quality assessment was based on seven criteria: random se- 


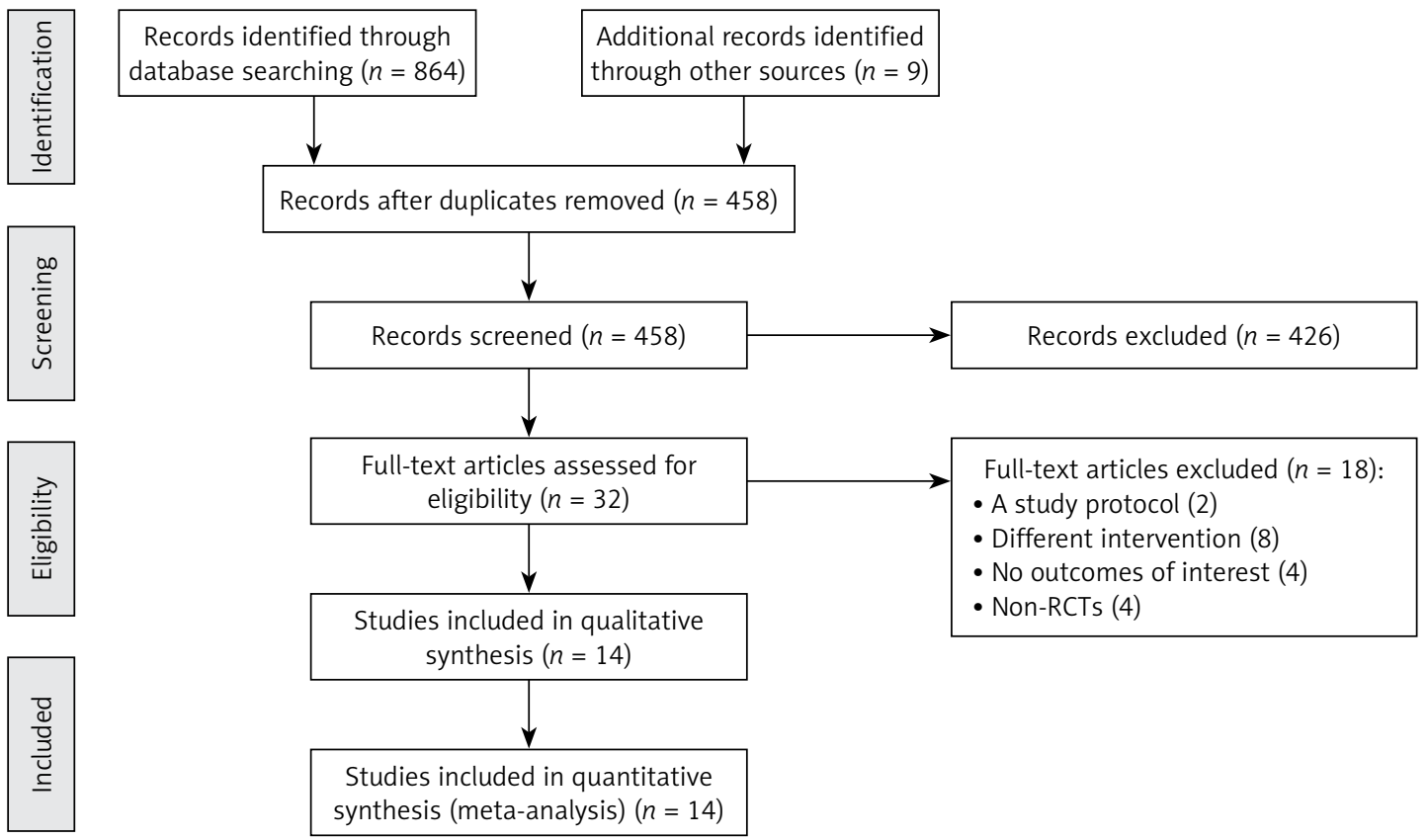

Figure 1. Preferred Reporting Items for Systematic Reviews and Meta-Analyses (PRISMA) flow diagram

quence generation, allocation concealment, blinding of participants and personnel, blinding of outcome assessment, incomplete outcome data, selective reporting and intention to treat analysis $[25,26]$.

\section{Outcome measures}

The primary outcomes measured in this metaanalysis were the 6-min walk distance and peak $\mathrm{VO}_{2}$ consumption of $\mathrm{HF}$ patients after receiving CRT. The secondary outcome was the clinical treatment response rate and improvement in quality of life. Outcomes were recorded at baseline and after intervention.

\section{Statistical analysis}

Standardized differences in the change from baseline between the treatment groups were used as the measure of effect size. Selected RCTs that compared the treatment effect of TriV with that of BiV and studies which compared the effect of BiV with that of left or right univentricular pacing (LUV/RUV) were analyzed separately. Subgroup analysis was performed for all LUV and RUV outcomes for univentricular pacing.

Study heterogeneity was presented using a $\chi^{2}$ based Cochran's $\mathrm{Q}$ statistic and $R^{2}$. For the $\mathrm{Q}$ statistic, $p$-values $<0.10$ were considered statistically significant for heterogeneity. For the $R^{2}$ statistic, heterogeneity was assessed as follows: no heterogeneity $(R=0-25 \%)$, moderate heterogeneity $\left(R^{2}=25-50 \%\right)$, large heterogeneity $\left(R^{2}=50-75 \%\right)$, and extreme heterogeneity $\left(R^{2}=75-100 \%\right)$. Pooled estimates of the standardized difference in means were determined using the DerSimonian-Laird ran- dom-effects model [24]. A two-sided $p$-value of $<0.05$ was considered significant. Sensitivity analysis was conducted using the leave-one-out approach. Publication bias was assessed if more than 10 studies were included in the meta-analysis for each outcome [27]. All analyses were performed using the Comprehensive Meta-Analysis statistical software, version 2.0 (Biostat, Englewood, NJ, USA).

\section{Results}

\section{Characteristics of selected RCTs}

A total of 864 studies were identified, of which 32 full text articles were finally assessed for eligibility. Of these, 4 studies were not RCTs, 4 studies did not report outcomes of interest, 8 studies had different interventions, and 2 studies were excluded for being a study protocol (Figure 1). Of the 14 RCTs which were included in the final analysis, six were cross-over trials $[19,21,28-31]$. Three RCTs compared the effect of TriV to that of BiV $[23,29$, 30], and the sample size ranged from 18 to 306 patients. The mean or median age ranged from 59 to 73 years, and the studies had a majority of male participants. Three of the studies reported that diabetes mellitus (DM) and hypertension were the most prevalent co-morbidities among the study patients. The duration over which outcomes were measured ranged from 12 weeks to 3 years after the intervention (Table I).

\section{Primary outcome measures}

There was no heterogeneity across studies which reported 6-min walk distance, regardless of wheth- 


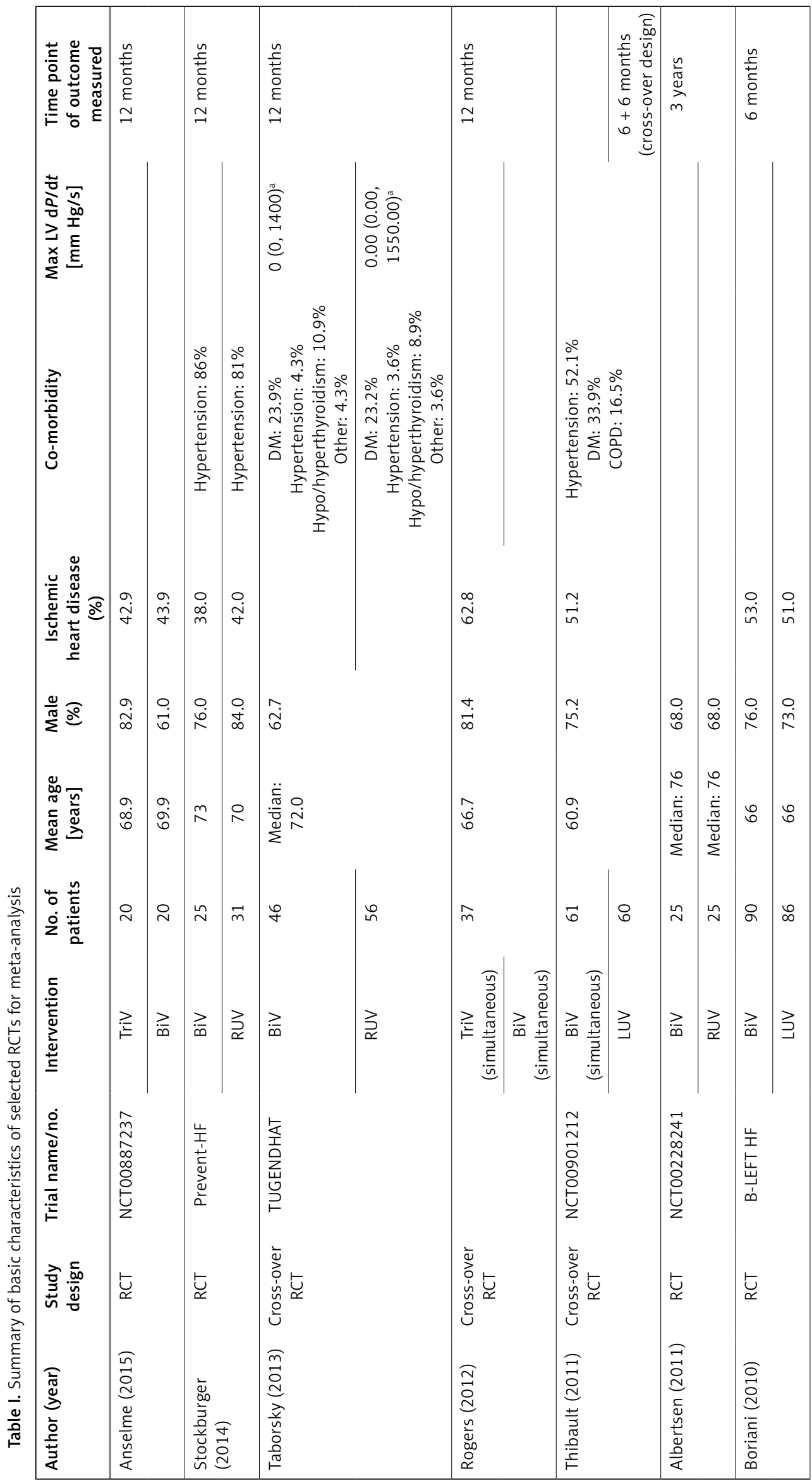




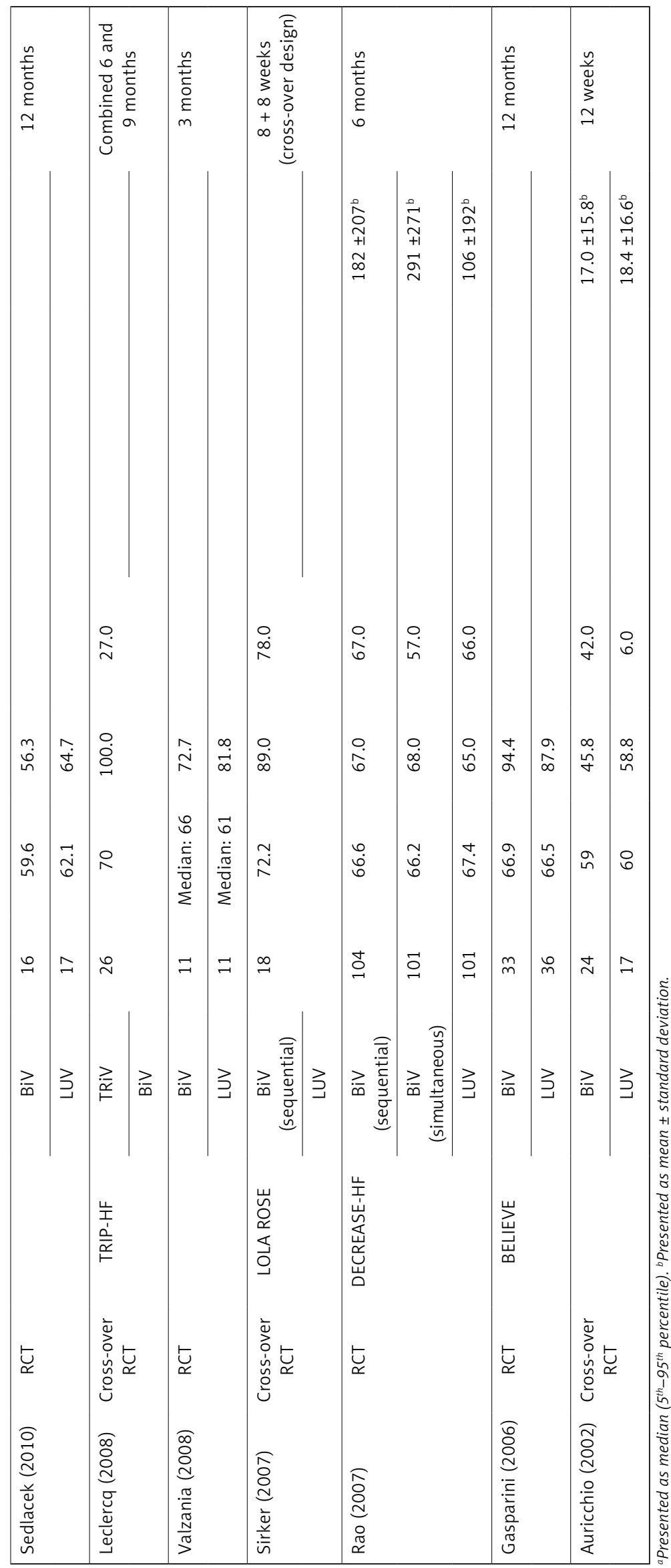


er the study compared BiV vs. LUV/RUV $\left(R^{2}=0 \%\right.$, $p=0.530)$ or TriV vs. BiV $\left(R^{2}=0 \%, p=0.373\right)$. Patients who received BiV showed no significant improvement in the 6-min walk distance compared to patients treated with univentricular pacing (standardized difference in means $=0.049,95 \% \mathrm{Cl}$ : -0.119 to $0.217, p=0.566)$. Similarly, patients treated with TriV showed no significant improvement in 6-min walk distance compared to patients treated with BiV (standardized difference in means $=0.035$, 95\% Cl: -0.270 to 0.340, $p=0.822$ ) (Figure $2 \mathrm{~A}$ ).

Patients in the BiV group had a greater change in peak $\mathrm{VO}_{2}$ compared to patients in the LUV/RUV group, although this was not statistically significant (standardized difference in means $=0.306$, $95 \% \mathrm{Cl}:-0.002$ to $0.614, p=0.052$ ). Comparison of the change in peak $\mathrm{VO}_{2}$ between the TriV and BiV groups was only performed in one RCT, and there was no significant difference between the two groups (Figure $2 \mathrm{~B}$ ).

\section{Secondary outcome measures}

There was only mild heterogeneity across the three trials which compared left ventricular ejec- tion fraction (LVEF) in the TriV and BiV groups $\left(R^{2}=11.2 \%, p=0.324\right)$. On the other hand, there was moderate heterogeneity across eight trials which compared LVEF in the BiV and the LUV/RUV groups $\left(I^{2}=38.6 \%, p=0.122\right)$. The LVEF in BiV-treated patients was similar to that of LUV/RUV-treated patients (standardized difference in means = $0.147,95 \% \mathrm{Cl}:-0.041$ to $0.335, p=0.125)$. However, patients in the TriV group had a significantly higher LVEF compared to patients in the BiV group (standardized difference in means $=0.647,95 \% \mathrm{Cl}$ : 0.313 to $0.982, p<0.001$ ) (Figure $3 \mathrm{~A}$ ).

There was no significant heterogeneity across the studies which compared the quality of life in the BiV and LUV/RUV groups $\left(I^{2}=0 \%, p=0.689\right)$, or the studies which compared quality of life in the TriV and BiV groups $\left(I^{2}=0 \%, p=0.649\right)$. There was no difference in the change of quality of life between the BiV and LUV/RUV groups (standardized difference in means $=0.004,95 \% \mathrm{Cl}:-0.167$ to $0.174, p=0.966$ ) or between the TriV and BiV groups (standardized difference in means = $-0.133,95 \% \mathrm{Cl}$ : -0.438 to $0.172, p=0.392$ ) (Figure $3 \mathrm{~B})$.

A

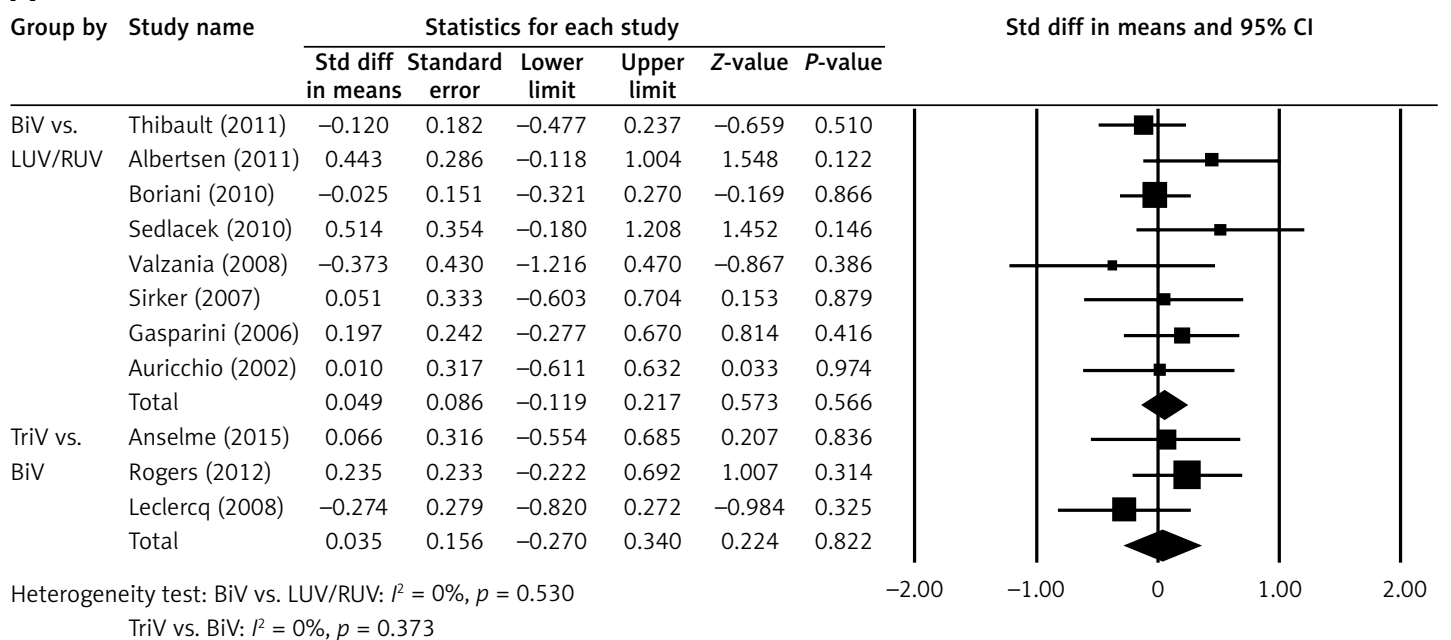

B

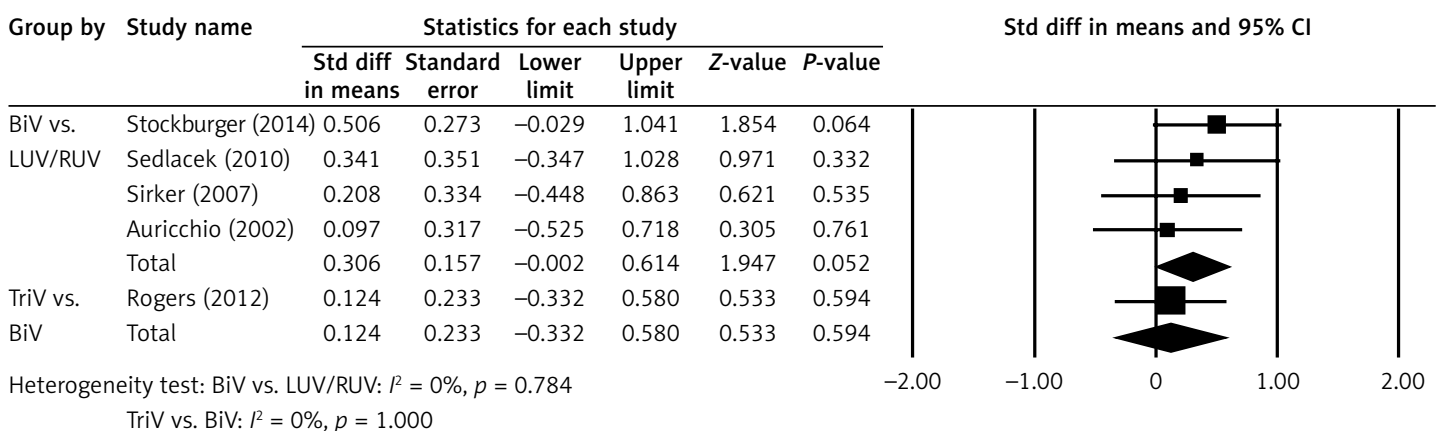

Figure 2. Forest plots for comparison of treatment effect of biventricular versus univentricular or triventricular CRT in patients with HF. A - 6-min walk distance, $\mathrm{B}-$ peak $\mathrm{VO}_{2}$ 


\section{Sensitivity analysis}

Results from the leave-one-out sensitivity analysis showed that the statistical significance and direction of association did not change when each study was removed one at a time for the comparison of BiV vs. LUV/RUV for walk distance (Figure 4 A). The direction of association changed when the Rogers et al. [30] study was removed for the comparison of TriV vs. BiV for walk distance (Figure 4 B). Figure $4 \mathrm{C}$ shows that Auricchio et al. [31] had an impact on peak $\mathrm{VO}_{2}$ consumption across four studies.

\section{Subgroup analysis}

Our subgroup analysis showed no significant difference in 6-min walk distance in four studies which compared the BiV and LUV groups (standardized difference in means $=0.010,95 \% \mathrm{Cl}$ : -0.166 to $0.187, p=0.909$ ) and one study which compared the BiV and RUV groups (standard- ized difference in means $=0.443,95 \% \mathrm{Cl}:-0.118$ to $1.004, p=0.122$ ) (Figure $5 \mathrm{~A}$ ). Our analysis showed no significant difference in peak $\mathrm{VO}_{2}$ in two studies which compared the BiV and LUV groups (standardized difference in means $=0.207$, $95 \% \mathrm{Cl}:-0.170$ to $0.584, p=0.283$ ) and one study which compared the BiV and RUV groups (standardized difference in means $=0.506,95 \% \mathrm{Cl}$ : -0.029 to $1.041, p=0.064$ ) (Figure $5 \mathrm{~B}$ ). We found no significant difference in the pooled estimate for LVEF in three studies which compared the BiV and LUV groups (standardized difference in means = $0.095,95 \% \mathrm{Cl}:-0.089$ to $0.280, p=0.310$ ), and two studies which compared the BiV and RUV groups (standardized difference in means $=0.384$, 95\% Cl: -0.283 to $1.050, p=0.259$ ) (Figure $5 \mathrm{C}$ ). Furthermore, we found no significant association between BiV or LUV treatment and quality of life (standardized difference in means $=-0.014$, $95 \% \mathrm{Cl}:-0.204$ to $0.176, p=0.885$ ) (Figure $5 \mathrm{D}$ ).

A

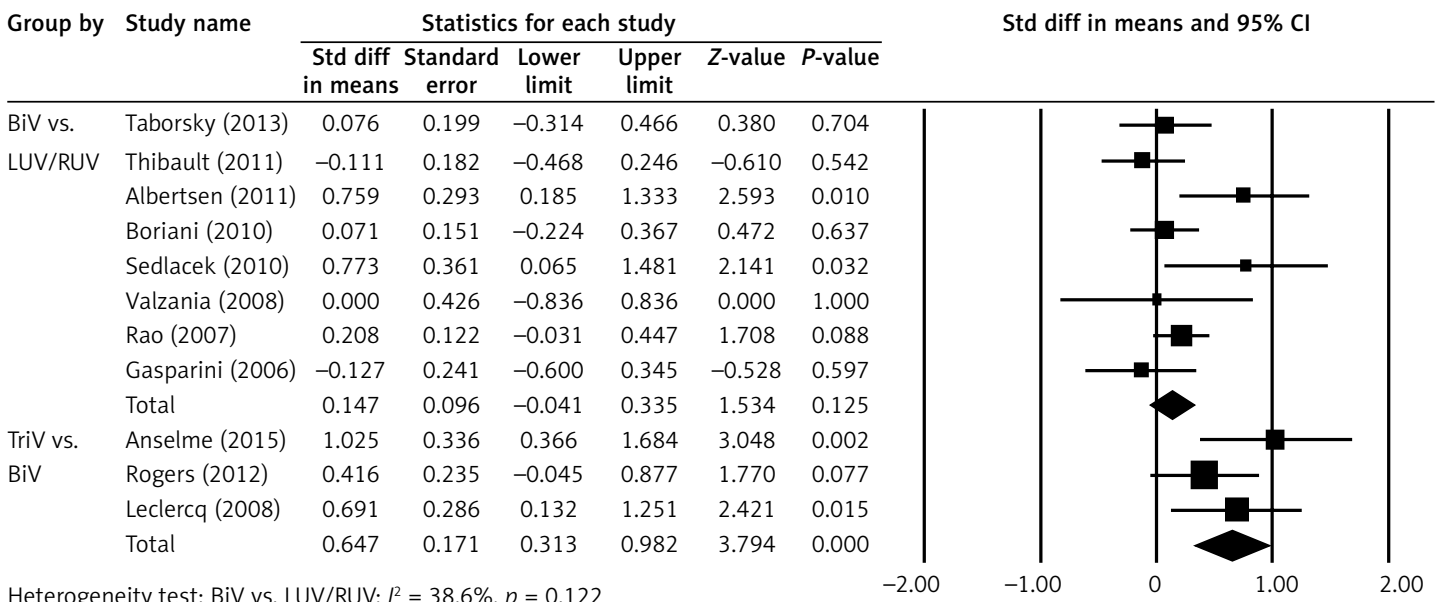

Heterogeneity test: BiV vs. LUV/RUV: $R^{2}=38.6 \%, p=0.122$

TriV vs. BiV: $P^{2}=11.2 \%, p=0.324$

B

\begin{tabular}{|c|c|c|c|c|c|c|c|c|c|}
\hline \multirow[t]{2}{*}{ Group by } & \multirow[t]{2}{*}{ Study name } & \multicolumn{5}{|c|}{ Statistics for each study } & & \multirow[t]{2}{*}{ Std diff in means and $95 \% \mathrm{Cl}$} & \\
\hline & & $\begin{array}{l}\text { Std diff } \\
\text { in means }\end{array}$ & $\begin{array}{c}\text { Standard } \\
\text { error }\end{array}$ & $\begin{array}{c}\text { Lower } \\
\text { limit }\end{array}$ & $\begin{array}{l}\text { Upper } \\
\text { limit }\end{array}$ & Z-value & $P$-value & & \\
\hline BiV vs. & Taborsky (2013) & 0.078 & 0.199 & -0.312 & 0.469 & 0.394 & 0.694 & & 1 \\
\hline \multirow[t]{7}{*}{ LUV/RUV } & Thibault (2011) & -0.106 & 0.182 & -0.463 & 0.250 & -0.584 & 0.559 & & \\
\hline & Boriani (2010) & 0.000 & 0.151 & -0.296 & 0.296 & 0.000 & 1.000 & & \\
\hline & Sedlacek (2010) & 0.317 & 0.350 & -0.370 & 1.004 & 0.904 & 0.366 & & \\
\hline & Valzania (2008) & -0.479 & 0.432 & -1.327 & 0.368 & -1.109 & 0.268 & & \\
\hline & Sirker (2007) & 0.360 & 0.336 & -0.299 & 1.018 & 1.070 & 0.285 & & \\
\hline & Auricchio (2002) & -0.149 & 0.317 & -0.771 & 0.473 & -0.470 & 0.638 & & \\
\hline & Total & 0.004 & 0.087 & -0.167 & 0.174 & 0.042 & 0.966 & & \\
\hline TriV vs. & Anselme (2015) & -0.048 & 0.316 & -0.668 & 0.572 & -0.152 & 0.879 & & \\
\hline \multirow[t]{3}{*}{ BiV } & Rogers (2012) & -0.292 & 0.234 & -0.751 & 0.166 & -1.251 & 0.211 & & \\
\hline & Leclercq (2008) & 0.026 & 0.277 & -0.518 & 0.569 & 0.093 & 0.926 & & \\
\hline & Total & -0.133 & 0.156 & -0.438 & 0.172 & -0.855 & 0.392 & & \\
\hline \multicolumn{7}{|c|}{ Heterogeneity test: BiV vs. LUV/RUV: $I^{2}=0 \%, p=0.689$} & -2.00 & -1.00 & 2.00 \\
\hline
\end{tabular}

Figure 3. Forest plots for comparison of treatment effect of biventricular versus univentricular or triventricular CRT in patients with HF. A - Left ventricular ejection fraction, B - quality of life 
A

Study name Statistics with study removed

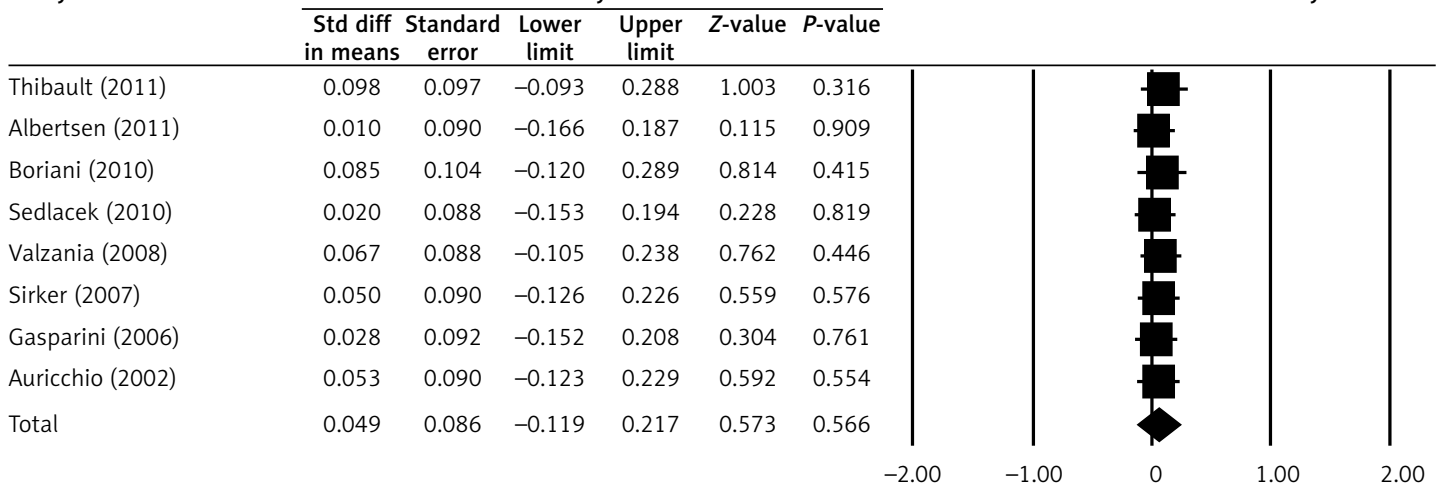

B

Study name Statistics with study removed

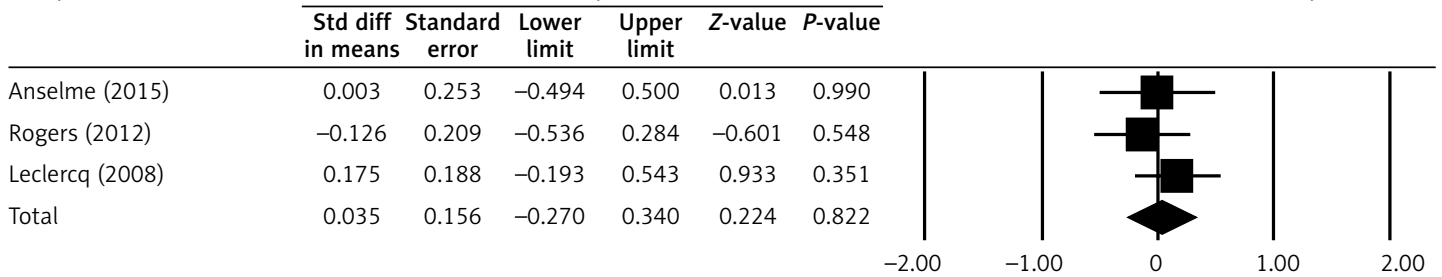

C

Study name

Statistics with study removed

Std diff in means and $95 \% \mathrm{Cl}$ with study removed

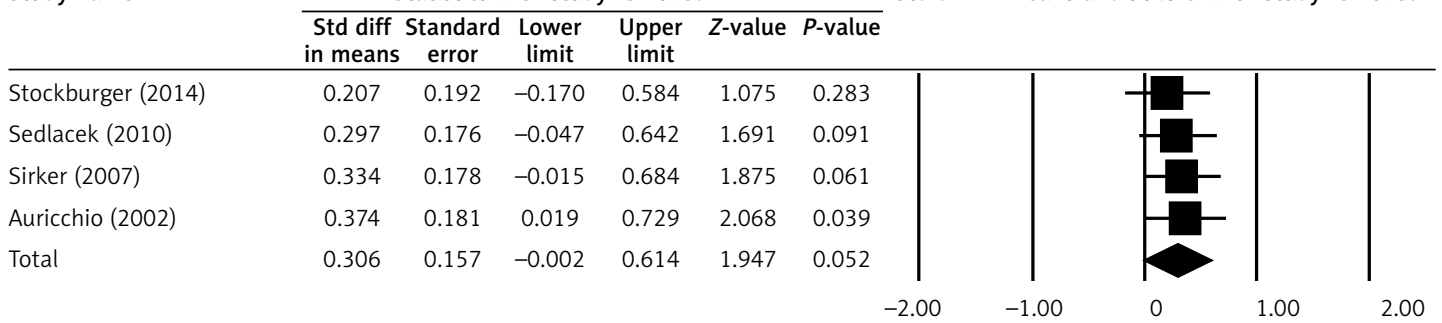

Figure 4. Sensitivity analysis for treatment effect of biventricular versus univentricular or triventricular CRT in patients with HF. A - 6-min walk distance (BiV vs. LUV/RUV), B - 6-min walk distance (TriV vs. BiV), and C - peak $\mathrm{VO}_{2}$ (BiV vs. LUV/RUV)

\section{Publication bias}

Publication bias was not assessed since less than 10 studies were included in the meta-analysis for each outcome.

\section{Quality assessment}

Quality assessment was performed for all 14 included studies (Figure 6). Most of the studies had an unclear bias for allocation concealment (Figure 6 A), except for the Boriani et al. and the Leclercq et al. studies [20, 29]. For treatment therapies such as those included in this analysis, it is difficult, and unethical, to achieve allocation concealment since the physicians need to assess the different treatments based on the condition of individual patients.
All the studies except for Rogers et al. [30] had an unclear or high risk of performance bias. Complete blinding of participants and personnel for interventional treatments was difficult due to ethical reasons and the health conditions of individual patients. In general, Figure 6 A shows that over half of the studies had a low risk of bias in terms of random sequencing, attrition, reporting bias and intention-to-treat analysis, suggesting that the quality of our analysis was adequate.

\section{Discussion}

This meta-analysis compared the clinical and functional outcomes of CRT in 14 studies which used univentricular, biventricular, or triventricular pacing to treat HF patients. There was no signif- 
A

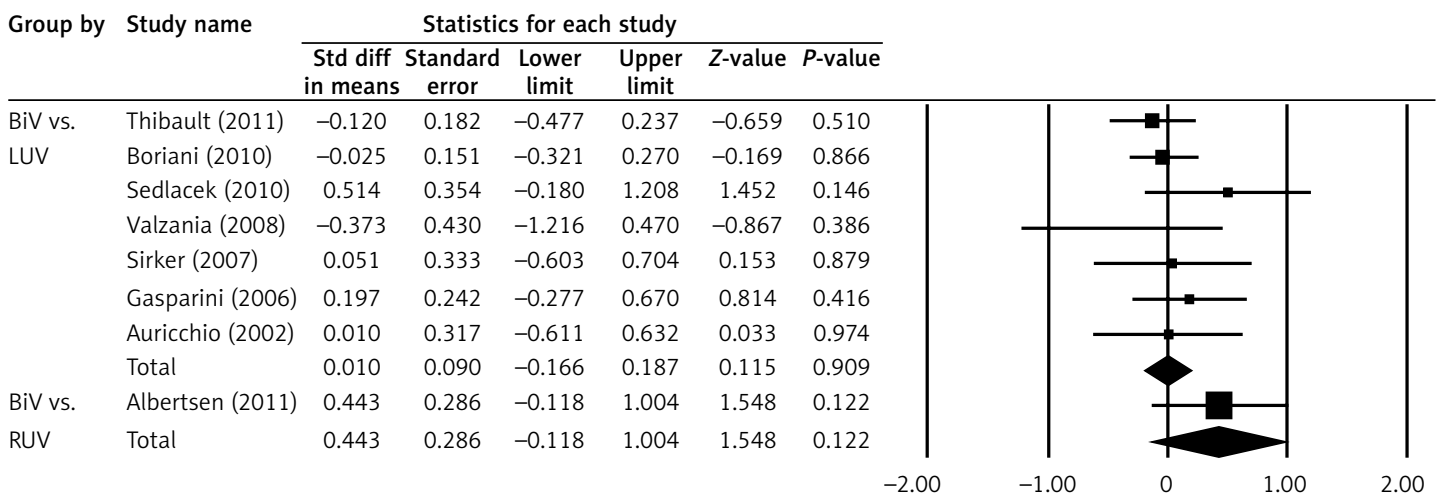

B

Group by Study name $\quad$ Statistics for each study

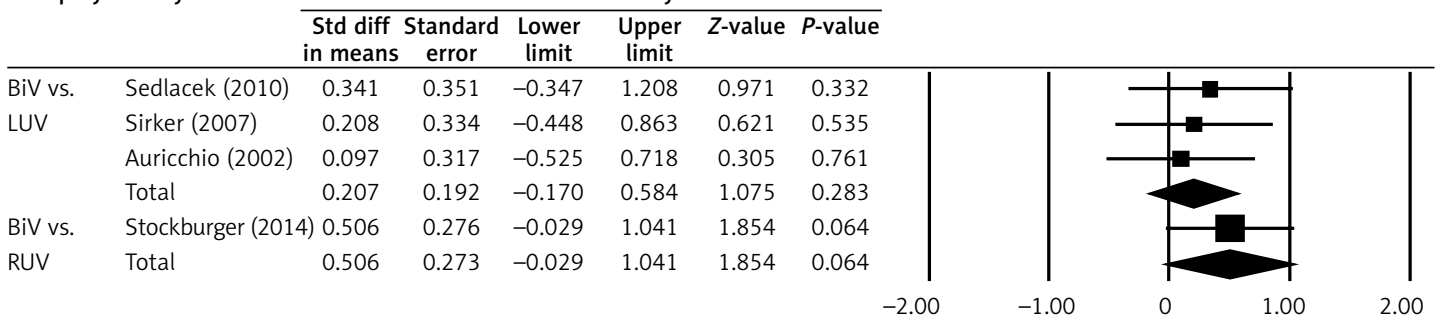

C

Group by Study name Statistics for each study

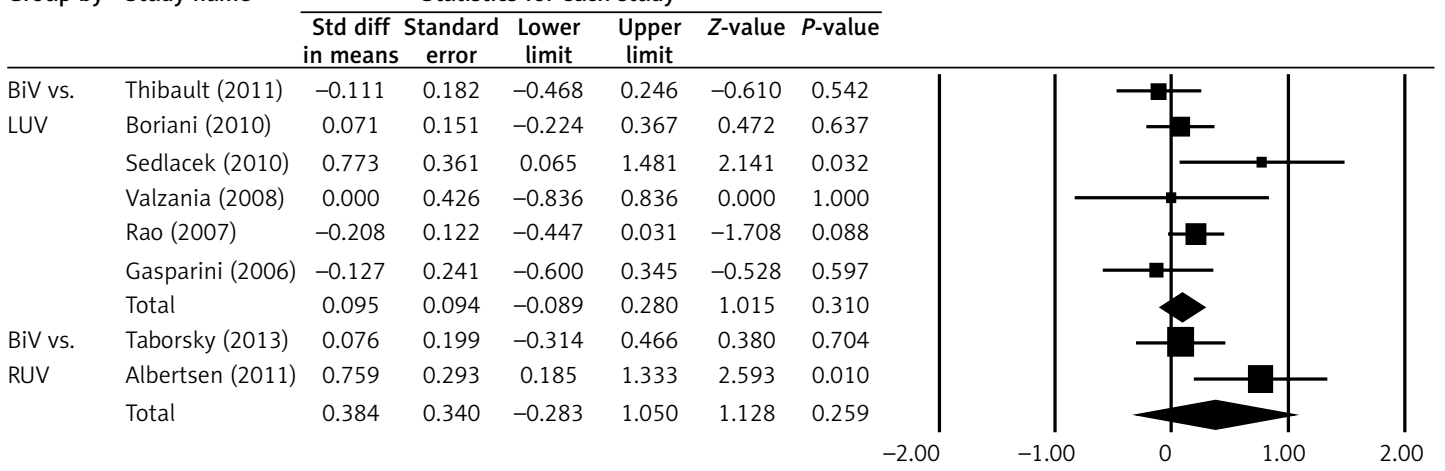

D

Group by Study name $\quad$ Statistics for each study

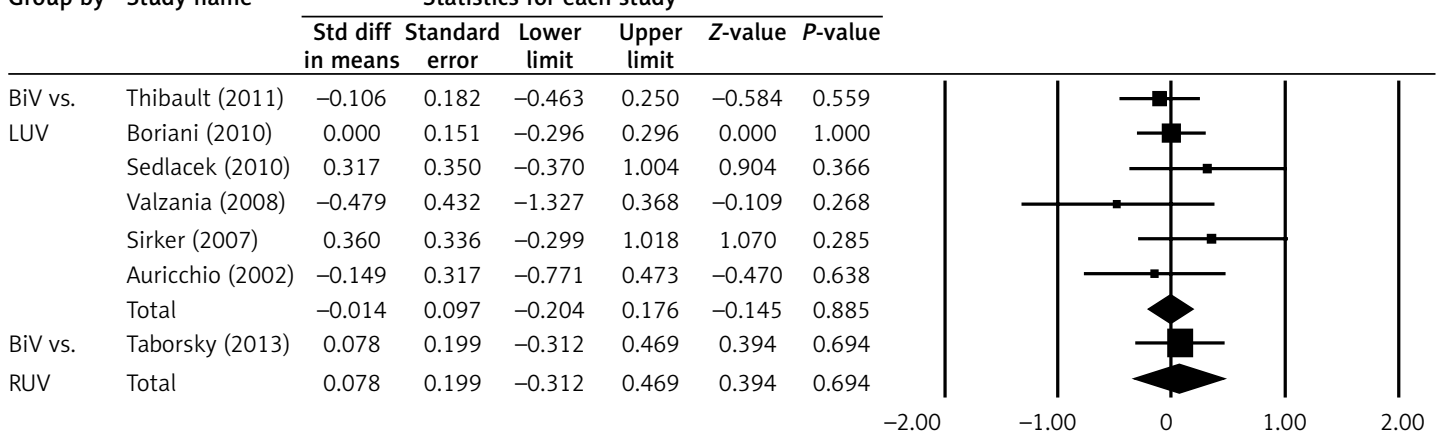

Figure 5. Subgroup analysis for treatment effect of biventricular versus univentricular CRT in patients with HF. A - 6-min walk distance, $\mathbf{B}$ - peak $\mathrm{VO}_{2}, \mathbf{C}$ - left ventricular ejection fraction, $\mathbf{D}$ - quality of life 
A

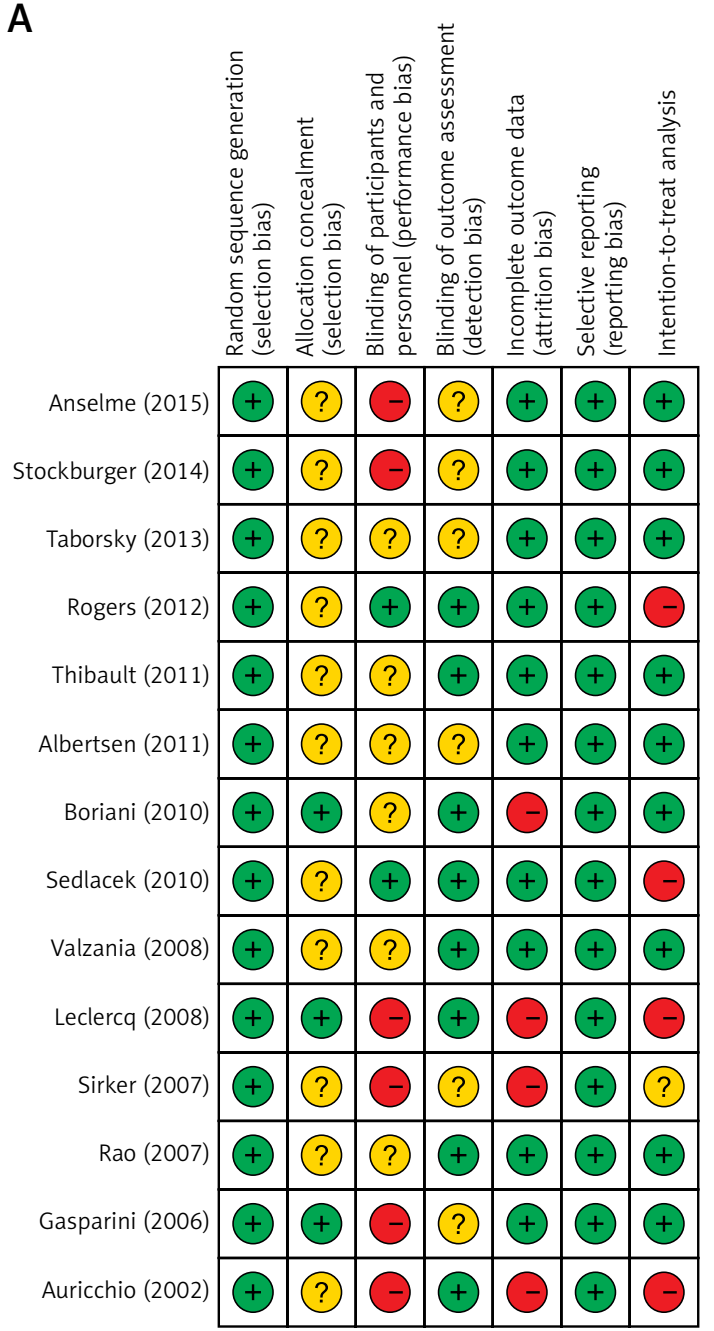

B

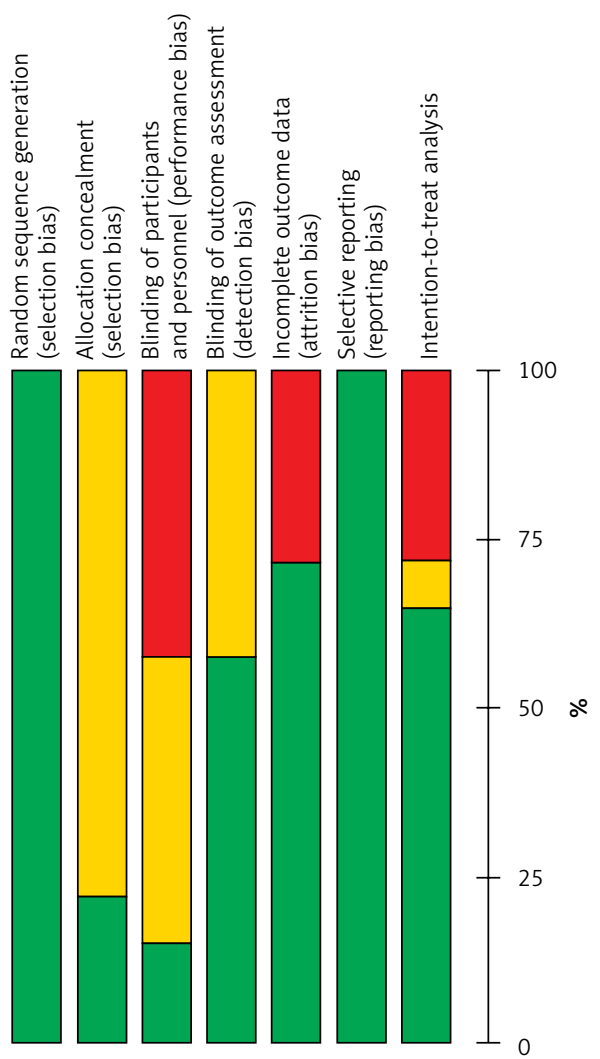

$\square$ Low risk of bias $\square$ Unclear risk of bias $\square$ High risk of bias

Figure 6. Quality assessment on (A) risk of bias for individual studies, and (B) summary of included studies

icant differences in the 6-min walking distance, change in peak $\mathrm{VO}_{2}$ consumption or quality of life between patients who received univentricular, biventricular, or triventricular pacing. However, patients who received triventricular CRT had a significant improvement in LVEF compared to patients who received biventricular pacing.

Although a number of studies demonstrated that BiV pacing was associated with superior outcomes compared to conventional CRT [32], LUV pacing [33], and RUV pacing in patients without advanced HF [34], other studies reported no significant difference in improvement in NYHA scores and reverse remodeling between patients who received BiV pacing and those who received LUV pacing [20, 21], as well as between those who received BiV pacing and those who received RUV pacing [28]. Additionally, patients who failed to respond to BiV pacing responded to LUV pacing [19]. Inconsistencies in comparisons between LUV and BiV pacing modalities have been attributed to differences in the LV activation pattern, which could be differentially affected by the atrioventricular (AV) programming or atrial pacing [35].

TriV pacing is a relatively novel technique that may provide a benefit in ventricular remodeling compared to conventional CRT. TriV was recently shown to result in a higher proportion of patients with a gain in LVEF of more than 5\%, 10\% and 15\% compared to conventional CRT [23]. These data were consistent with previous studies showing that TriV resulted in significantly higher 6-minute walk distance, LV end-systolic volume, and ejection fraction [30] and significantly more LV reverse remodeling [29] compared to the BiV modality.

Our study pooled data from only RCTs to minimize potential bias for a more robust result. Our sensitivity analysis using the leave-one-out approach showed that exclusion of one study did not change our results significantly. Subgroup analysis by stratification of the LUV and RUV univentricular pacing groups was performed, and showed no significant difference in the assessed outcomes between the RUV and BiV groups or between the 
LUV and BiV groups. To the best of our knowledge, ours is the first meta-analysis that compared the clinical and functional efficacy of CRT using different pacing methods. Further studies are necessary to validate these conclusions.

Our meta-analysis had a number of limitations. Firstly, our pooled data set was small, since only a limited number of studies fit our inclusion criteria. Some outcomes were analyzed with only one or two studies, which could lead to a high probability of bias. Secondly, there was high heterogeneity for the secondary outcomes. This may also be caused by differences in the etiology of HF between studies. Subgroup analysis based on etiology of HF was not performed due to insufficient information for individual patients. Large differences in follow-up time (ranging from 12 weeks to 3 years) may also be a potential reason for heterogeneity, since HF is a chronic disease. Future studies are necessary to assess the efficacy of TriV pacing with respect to survival and longterm complications. A systematic comparison of the efficacy of CRT with medical therapy is clinically significant for optimizing treatment for HF in patients who fail to respond or are intolerant to conventional treatment.

In conclusion, our meta-analysis suggested that TriV CRT is an attractive alternative to univentricular or BiV pacing for the improvement of LVEF. It is necessary to conduct further large randomized trials to validate our present data.

\section{Acknowledgments}

This study was supported by the Department of Education of Guangdong province, China (\#YQ2015138), the Guangdong Natural Science Foundation, China (\#2014A030310077, S2013010014478), the Guangzhou Science Technology and Innovation commission (\#2014Y200085, 2013J4500017), the Guangdong Department of Science and Technology, China (\#2015A020215037), and Guangzhou Medical University (\#2013C33).

\section{Conflict of interest}

The authors declare no conflict of interest.

\section{References}

1. Kim AS, Johnston SC. Global variation in the relative burden of stroke and ischemic heart disease. Circulation 2011; 124: 314-23.

2. Hunt SA, Baker DW, Chin MH, et al.; American College of Cardiology/American Heart Association Task Force on Practice $\mathrm{G}$, International Society for $\mathrm{H}$, Lung T, Heart Failure Society of A. ACC/AHA Guidelines for the Evaluation and Management of Chronic Heart Failure in the Adult: Executive Summary A Report of the American College of Cardiology/American Heart Association Task
Force on Practice Guidelines (Committee to Revise the 1995 Guidelines for the Evaluation and Management of Heart Failure): Developed in Collaboration With the International Society for Heart and Lung Transplantation; Endorsed by the Heart Failure Society of America. Circulation 2001; 104: 2996-3007.

3. Sweeney MO, Hellkamp AS, Ellenbogen KA, et al.; Investigators MOST. Adverse effect of ventricular pacing on heart failure and atrial fibrillation among patients with normal baseline QRS duration in a clinical trial of pacemaker therapy for sinus node dysfunction. Circulation 2003; 107: 2932-7.

4. Healy DG, Hargrove M, Doddakulla K, Hinchion J, O’Donnell A, Aherne T. Impact of pacing modality and biventricular pacing on cardiac output and coronary conduit flow in the post-cardiotomy patient. Interact Cardiovasc Thorac Surg 2008; 7: 805-8.

5. Beshai JF, Khunnawat C, Lin AC. Mechanical dyssynchrony from the perspective of a cardiac electrophysiologist. Curr Opin Cardiol 2008; 23: 447-51.

6. Straka F, Pirk J, Pindak M, et al. The hemodynamic effect of right ventricle (RV), RT3DE targeted left ventricle (LV) and biventricular (BIV) pacing in the early postoperative period after cardiac surgery. Pacing Clin Electrophysiol 2011; 34: 1231-40.

7. Epstein AE, DiMarco JP, Ellenbogen KA, et al.; American College of Cardiology/American Heart Association Task Force on Practice G, American Association for Thoracic S, Society of Thoracic S. ACC/AHA/HRS 2008 Guidelines for Device-Based Therapy of Cardiac Rhythm Abnormalities: a report of the American College of Cardiology/American Heart Association Task Force on Practice Guidelines (Writing Committee to Revise the ACC/AHA/ NASPE 2002 Guideline Update for Implantation of Cardiac Pacemakers and Antiarrhythmia Devices) developed in collaboration with the American Association for Thoracic Surgery and Society of Thoracic Surgeons. J Am Coll Cardiol 2008; 51: e1-62.

8. Auricchio A, Stellbrink C, Butter C, et al.; Pacing Therapies in Congestive Heart Failure IISG, Guidant Heart Failure Research G. Clinical efficacy of cardiac resynchronization therapy using left ventricular pacing in heart failure patients stratified by severity of ventricular conduction delay. J Am Coll Cardiol 2003; 42: 2109-16.

9. Ritter O, Koller ML, Fey B, et al. Progression of heart failure in right univentricular pacing compared to biventricular pacing. Int J Cardiol 2006; 110: 359-65.

10. Hoppe UC. Resynchronization therapy in the context of atrial fibrillation: benefits and limitations. J Interv Card Electrophysiol 2007; 18: 225-32.

11. Albertsen AE, Mortensen PT, Jensen HK, Poulsen SH, Egeblad $\mathrm{H}$, Nielsen JC. Adverse effect of right ventricular pacing prevented by biventricular pacing during longterm follow-up: a randomized comparison. Eur J Echocardiogr 2011; 12: 767-72.

12. Cleland JG, Daubert JC, Erdmann E, et al.; Cardiac Resynchronization-Heart Failure Study I. The effect of cardiac resynchronization on morbidity and mortality in heart failure. N Engl J Med 2005; 352: 1539-49.

13. Moss AJ, Hall WJ, Cannom DS, et al.; Investigators M-CT. Cardiac-resynchronization therapy for the prevention of heart-failure events. N Engl J Med 2009; 361: 1329-38.

14. Vollmann D, Luthje L, Schott P, Hasenfuss G, Unterberg-Buchwald C. Biventricular pacing improves the blunted force-frequency relation present during univentricular pacing in patients with heart failure and conduction delay. Circulation 2006; 113: 953-9. 
15. van Gelder BM, Meijer A, Bracke FA. Stimulation rate and the optimal interventricular interval during cardiac resynchronization therapy in patients with chronic atrial fibrillation. Pacing Clin Electrophysiol 2008; 31: 569-74.

16. Sedlacek K, Burianova L, Mlcochova H, Peichl P, Marek T, Kautzner J. Isolated left ventricular pacing results in worse long-term clinical outcome when compared with biventricular pacing: a single-centre randomized study. Europace 2010; 12: 1762-8.

17. Valzania C, Rocchi G, Biffi M, et al. Left ventricular versus biventricular pacing: a randomized comparative study evaluating mid-term electromechanical and clinical effects. Echocardiography 2008; 25: 141-8.

18. Gasparini M, Bocchiardo M, Lunati M, et al.; Investigators B. Comparison of 1-year effects of left ventricular and biventricular pacing in patients with heart failure who have ventricular arrhythmias and left bundle-branch block: the Bi vs Left Ventricular Pacing: an International Pilot Evaluation on Heart Failure Patients with Ventricular Arrhythmias (BELIEVE) multicenter prospective randomized pilot study. Am Heart J 2006; 152: 155 e1-7.

19. Thibault B, Ducharme A, Harel F, et al.; Evaluation of Resynchronization Therapy for Heart Failure I. Left ventricular versus simultaneous biventricular pacing in patients with heart failure and a QRS complex $>/=120$ milliseconds. Circulation 2011; 124: 2874-81.

20. Boriani G, Kranig W, Donal E, et al.; Group BLHs. A randomized double-blind comparison of biventricular versus left ventricular stimulation for cardiac resynchronization therapy: the Biventricular versus Left Univentricular Pacing with ICD Back-up in Heart Failure Patients (B-LEFT HF) trial. Am Heart J 2010; 159: 1052-8e1.

21. Sirker A, Thomas M, Baker S, et al. Cardiac resynchronization therapy: left or left-and-right for optimal symptomatic effect--the LOLA ROSE study. Europace 2007; 9: 862-8.

22. Gold MR, Leman RB, Wold N, Sturdivant JL, Yu Y. The effect of left ventricular electrical delay on the acute hemodynamic response with cardiac resynchronization therapy. J Cardiovasc Electrophysiol 2014; 25: 624-30.

23. Anselme F, Bordachar P, Pasquie JL, et al. Safety, feasibility, and outcome results of cardiac resynchronization with triple-site ventricular stimulation compared to conventional cardiac resynchronization. Heart Rhythm 2016; 13: 183-9.

24. Leclercq C, Gadler F, Kranig W, et al. A randomized comparison of triple-site versus dual-site ventricular stimulation in patients with congestive heart failure. J Am Coll Cardiol 2008; 51: 1455-62.

25. Collaboration TC. Cochrane Handbook for Systematic Reviews of Interventions. Version 5.1.0. 2011 [updated March, 2011]. Available from: http://www.mrc-bsu.cam. ac.uk/cochrane/handbook/.

26. DerSimonian R, Laird N. Meta-analysis in clinical trials. Control Clin Trials 1986; 7: 177-88.

27. Sterne JA, Sutton AJ, loannidis JP, et al. Recommendations for examining and interpreting funnel plot asymmetry in meta-analyses of randomised controlled trials. BMJ 2011; 343: d4002.

28. Taborsky M, Rihova D, Mraz T, et al. TUGENDHAT: a pilot randomized study on effects of biventricular pacing in patients with bradycardia pacing indication and normal systolic function on heart failure, atrial fibrillation and quality of life (results of 12 month follow-up). Bratisl Lek Listy 2013; 114: 323-9.

29. Leclercq C, Gadler F, Kranig W, et al.; Group T-HS. A randomized comparison of triple-site versus dual-site ven- tricular stimulation in patients with congestive heart failure. J Am Coll Cardiol 2008; 51: 1455-62.

30. Rogers DP, Lambiase PD, Lowe MD, Chow AW. A randomized double-blind crossover trial of triventricular versus biventricular pacing in heart failure. Eur J Heart Fail 2012; 14: 495-505.

31. Auricchio A, Stellbrink C, Sack S, et al.; Pacing Therapies in Congestive Heart Failure Study G. Long-term clinical effect of hemodynamically optimized cardiac resynchronization therapy in patients with heart failure and ventricular conduction delay. J Am Coll Cardiol 2002; 39: 2026-33.

32. Shetty AK, Sohal M, Chen Z, et al. A comparison of left ventricular endocardial, multisite, and multipolar epicardial cardiac resynchronization: an acute haemodynamic and electroanatomical study. Europace 2014; 16: 873-9.

33. Rao RK, Kumar UN, Schafer J, Viloria E, De Lurgio D, Foster E. Reduced ventricular volumes and improved systolic function with cardiac resynchronization therapy: a randomized trial comparing simultaneous biventricular pacing, sequential biventricular pacing, and left ventricular pacing. Circulation 2007; 115: 2136-44.

34. Stockburger $M$, de Teresa E, Lamas G, et al. Exercise capacity and $\mathrm{N}$-terminal pro-brain natriuretic peptide levels with biventricular vs. right ventricular pacing for atrioventricular block: results from the PREVENT-HF German Substudy. Europace 2014; 16: 63-70.

35. Gold MR, Niazi I, Giudici M, et al. A prospective, randomized comparison of the acute hemodynamic effects of biventricular and left ventricular pacing with cardiac resynchronization therapy. Heart Rhythm 2011; 8: 685-91. 